HOW, a Colombian Journal of Teachers of English. No. 5. (pp. 63-69). (ISSN: 0120-5927). 1999.

APA citation style: Benavides B., Jorge E. (1999). Exploring Materials and Activities for CALL. HOW, a Colombian Journal of Teachers of English (5), 63-69.

\title{
Exploring Materials and Activities for CALL
}

\author{
Jorge E. Benavides B. (joelbebu@gmail.com) \\ Departamento de Lingüística e Idiomas \\ Universidad de Nariño, San Juan de Pasto, Colombia
}

The acquisition and use of personal computers by faculty staff and students has increased dramatically during the $80 \mathrm{~s}$ and $90 \mathrm{~s}$. Commercial software such as word processors and databases has been widely used for supplementary language instruction in the EFL class setting. Moreover, educational software especially designed for foreign and second language learning has been increasingly available everywhere. Here, the purpose is to give an idea of how much can be done with a very small sample of programs like in the initial stages of CALL. The idea is to continue giving hints (on up-coming issues) on how the software available can be used to take the most advantage of learning for our students.

\section{Computer-based activities}

Since there is as yet no special CALL methodology, the effectiveness of the activities that the teacher can develop for the language learner have to be largely based on the way computers are used in the language learning setting and on what both teachers and students can do with them in a self-access system.

Most of the activities now used by most teachers and students are a replica of the traditional activities developed with textbooks and other materials in spite of the initial efforts made in order to introduce CALL into the language curriculum (Benavides 1998). However, there are some important differences in terms of what computers can do which cannot be done with the textbook or other types of materials. These differences come from the fact that computers can do things such as memorizing, storing, stimulating, processing and manipulating information; providing immediate feedback to the students in their tasks, keeping records of their performance, and allowing easy and fast access to information by teachers and students which permits a more exploratory kind of work leading to discovery learning, supposedly resulting in more gains in terms of language learning.

What computers can do for the students, however has to be considered as a part of the interaction established among teachers and students via the computer itself. Therefore, what the computer can do is only important when the interaction between teacher and student is considered.

Since there is not $100 \%$ computer-based activity -and there is no need for such a thing yet, we have to seriously consider, as mentioned earlier for the sake of the development of a CALL methodology, what the teacher, student, and computer can do within CALL-based activities. Therefore, It has been suggested, for example that it is important to consider the work teachers and students can do before engaging in working with the computer (pre-computer work, i.e. the work done in the classroom), the work with the computer (computer work), and the work after working with the computer (post computer work), in a CALL situation.

\section{CALL Communicative activities}

As a reaction against the type of Programmed Instruction activities in CALL there have been some attempts at introducing more communicative activities with computers. For example, activities like simulations have proved very successful as providers of communicative input among learners. These types of tasks are then regarded as 
HOW, a Colombian Journal of Teachers of English. No. 5. (pp. 63-69). (ISSN: 0120-5927). 1999.

valid, meaningful and entertaining which may be due to the social aspect of communicative language teaching. Learners would be able to exhibit the satisfaction gained from interaction together when engaged in a meaningful communicative activity in CALL.

Working on the idea of the Krashen's 'Input Hypothesis' (1982) in which what is required for effective learning is a comprehensible input, we can assume that CALL programs that initiate activities in which the student is in control, will provide more chances for learning to happen. On the other hand, if the type of activities a program develops is that of the kind of formal or explicit instruction, then it only serves purposes no different from those of books.

Underwood (1984) stresses the fact that communicative and non-communicative aspects in CALL software can be incorporated as roles of materials (software) which in the end is what govern the computer. This distinction is in direct relation with the learning possibilities that the activities recreated with these kinds of materials will arise. Below, we can see the characteristics of communicative CALL and non- communicative CALL underlying language learning activities.

\section{Non-communicative CALL (programs recreating this type of activities)}

-Program incorporates grammatical sequencing

-Program judges to inform students of their errors

-Program is in control

-Subject matter is irrelevant to students

-Lesson is predetermined

-Student perceives task as a required lesson

-Student views task as identical to classroom activities

\section{Communicative CALL}

-Program does not impose grammatical sequencing

-Program judges more to provide helpful hints

-Student is in control

-Student relates to subject matter in a personal way

-Student creates his own learning experience

-Student perceives task as motivating supplement

-Student views task as a novel activity. (Underwood, 1984)

Some of the CALL activities directed to promote communication among the students can be made possible taking Brown and Yule's (1983), categories of oral discourse, as shown below (cited in Esling, 1991).

\section{Brown and Yule's task types}

1. Describing an object or photograph

2. Instruction how to draw a diagram

3. Instructing how to assemble a piece of equipment

4. Describing how a number of objects are to be arranged

\section{CALL tasks \\ Describing images in the data base; using hypermedia}

Drawing/designing with computer software; with 'drawing' or 'painting' programs of graphics software Setting up the computer by reading operating instruction, doing 'process' exercises.

Word processing with writing, formatting, printing, plotting programs 
HOW, a Colombian Journal of Teachers of English. No. 5. (pp. 63-69). (ISSN: 0120-5927). 1999.

\begin{tabular}{|l|l|} 
5. Giving route directions & $\begin{array}{l}\text { Using interactive simulations with graphics } \\
\text { programs }\end{array}$ \\
7. Giving and eye-witness account & $\begin{array}{l}\text { Reading close texts; reading/completing previously } \\
\text { written text files; describing a sequence of events } \\
\text { depicted in visuals }\end{array}$ \\
8. Expressing an opinion & $\begin{array}{l}\text { Playing computer simulations and recounting } \\
\text { computer crashes or other experiences using } \\
\text { written or oral reports. }\end{array}$ \\
9. Justifying a course of action & $\begin{array}{l}\text { Evaluating with the computer using problem solving, } \\
\text { questionnaires, surveys } \\
\text { Engaging in non-computer pedagogical application } \\
\text { with role-play }\end{array}$ \\
\hline
\end{tabular}

\section{Program types}

Programs suitable for language learning are nowadays available from many sources. Some of the most useful for teachers are those labelled 'authoring programs' which enable them to adapt or produce pedagogicallysound materials according to current classroom practice and classroom needs. Non-authoring or well-known 'dedicated' programs commercially available like word processors, adventure games and simulations which are not specifically designed for language learning are also widely used for language learning. In the end teachers and students know how to make good use of them.

Within the domain of CALL there exist a wide variety of software for recreating different types of activities for almost every language skill and linguistic aspect. CALL programs are available for grammar, vocabulary, reading and writing. However, there are no such programs for speaking or even listening, even though the technology seems to be developing fast enough to cope at low levels of speech recognition and speech production.

Program types can be classified according to different criteria, that is, the skills they promote, or the type of activities they develop; however, the teacher is ultimately the person who will have to make a choice in terms of which criteria to choose to make the software available for the learners, as it is the case in a self-access system. Here the teacher will recommend suitable programs for the individual needs of the students.

To give an idea of the availability of software we will concentrate on a very small part of program types for grammar and vocabulary. The following is a classification of CALL software according to the skill and the activity they promote.

\subsection{GRAMMAR}

For grammar there are gap-filling exercises like GAPIT or GAPFIL which may consist of single sentences in which the learner has to provide for the missing word. Also, there are multiple-choice programs like CHOICEMASTER where the computer is programmed to guide the learner towards the right answer.

- MATCHMASTER is another type of program used for practice with grammar in which the learners have to match two dependent and independent clauses only by selecting the two parts.

Activities generated by general-purpose programs like TESTMASTER in a multiple choice format can also be used to practice grammar or any other skills or linguistic aspect. 
HOW, a Colombian Journal of Teachers of English. No. 5. (pp. 63-69). (ISSN: 0120-5927). 1999.

\subsection{VOCABULARY}

Jones (1987) gives some suggestions on how to use programs for vocabulary learning. This type of programs for vocabulary are often considered highly attractive and motivating for the learners since most of them introduce some sort of game-like format. The following are just a few of the most widely known vocabulary programs.

\section{- CROSSWORD}

It is one of the most widely known programs and it works similarly to text-based puzzles. It depends on the ability of the teacher in creating puzzles with the target vocabulary for his classes.

\section{- HANGMAN}

In this program the learner tries to discover the hidden word by entering different letters. It is one of the most popular vocabulary games of which there are as many versions as game writers and authoring teachers.

\section{- WORDSPIN}

Used for word recognition and often considered as a 'speller trainer'. In this program the learners have to identify a word 'spinning' on the screen.

\section{- ALPHAGAME}

An alphabetical order game in which the learner has to 'guess' the word the computer is thinking of by typing words and finding out whether it is after or before in the dictionary based on the computer target.

\section{- WORDSQUARES}

The learner has to extract words (up, down, across or diagonally) from a square which may be hidden among other letters.

\section{- MINDWORD}

A more sophisticated type of program in which the learner has to guess the word the computer is thinking of by giving semantically contextualized hints on the word.

\section{- SCRABBLE}

It is a very effective computer game which usually includes around 20.000 build-in words in its dictionary with the possibility of introducing others for working as an authoring tool.

There are of course many more possibilities for grammar and vocabulary learning with different types of programs especially with multimedia where the integration of sound, moving video, graphics, and text seems to provide more interactive opportunities for learning. Consequently, these types of activities recreated by the computer could develop different learning styles.

\subsection{ADVENTURE GAMES}

Another type of computer-generated activity comprises adventure games which fall within the problem-solving domain. The player comes across different possibilities from which he has to choose the best in order to complete a task and achieve a given goal. Successful 'negotiation' with the information within the game is very important. The motivating value of these types of programs is considerably high.

One example of adventure games is LONDON ADVENTURE (Hamilton, 1986), where the player must 'interact' in London (ask directions politely to passers-by) in order to find guidebooks providing information on London transport and department stores to purchase 10 last-minute gifts items before it is time to catch the plane home (the program sets a clock at the start of play). The player is provided with a certain sum in foreign 
HOW, a Colombian Journal of Teachers of English. No. 5. (pp. 63-69). (ISSN: 0120-5927). 1999.

currency, and traveller checks. In this type of games, for example, reading is practiced in a variety of ways and purposes.

In a self-access system, the learners could find different types of programs like the above mentioned, organized in such a way that they will be able to use them according to the skill involved and their level. McDonough (1993) gives us an example of how this could be organized in a resource centre.

CALL programs available for you to use

(Level: E=elementary, I=intermediate, $\mathbf{A}=$ =advanced.)

a. Vocabulary Practice

-Crossword Challenge (1 or 2 players) I/A

-Vocab (Which word or Skullman) E/IA

-Criss-Cross Quiz (2 players) E/I/A

-Screen-test First Certificate (word formation) I

-Screen-test Proficiency (key words) A

-Cambridge First Certificate (gap filling) I/A

b. Grammar Practice

-Screen-test First Certificate (sentence transformation) I

-Screen-test for Proficiency (sentence transformation) A

-Choice master E

-Criss-Cross Quiz (2 players) E/I/A

-Cambridge First Certificate (sentence requiting) I/A

-Reading practice E/I/A

-Storyboard Plus $\quad E / I$

-Storyboard I/A

-Cloze master E/I/A

-Speed-read I

-Screen-test First Certificate (space filling) I

-Screen-test Proficiency (space filling) A

-Cambridge First Certificate (reading) Close passage A

\section{c. Writing Practice}

-Screen-test First Certificate (dialogue building, Sentence completion) I

-Screen-test Proficiency (sentence completion) A

-WordStar (word processing) A

-Cambridge First Certificate (letter/dialogue) I

(Taken from McDonough, 1993:253)

\section{Evaluating CALL Software}

The teacher and the learners are seen as active participants of the evaluation part in using computers in the classroom or in a self-access system. For example, the teacher will have to be concerned with the following questions in the checklist, (taken from Rendall, 1991:35) if he is aware of his role as materials evaluator.

The following checklist to evaluate CALL software basically deals with how much flexible a piece of software is to be worth trying for CALL. If the answers in the first part are mostly affirmative, it means that the program may not be very flexible to be considered for use. Conversely, if the answers of the second part are affirmative, then we may be dealing with a useful program. 
HOW, a Colombian Journal of Teachers of English. No. 5. (pp. 63-69). (ISSN: 0120-5927). 1999.

I.

1. Is there a long introduction before you get to the main menu?

2. Are extensive graphics and jingles used in the introduction?

3. Do they take up more than $5-10$ seconds?

4. Does the program offer only one activity?

5 . Is each activity restricted to one methodology?

6. Is the vocabulary limited to one topic?

7. Do you have to work through the first activity to get to the second one?

II.

1. Does the information with the software give full details of vocabulary/expressions covered in the program?

2. Can the introductory graphics/jingles be avoided on a re-run?

3. Are the instructions of the screen enough to be able to work through the program without reference to the instruction booklet?

4. Is there a main menu?

5. Can you list all the available files?

6. Can you easily return to the main menu from the end of an activity?

7. Can the program be given a time limit?

8. Can the program be given a content limit?

9. Can the program be used for all abilities?

10. Does the program offer more than one approach?

The teacher also needs to be concerned with these two questions

1. How well does the vocabulary/content cover work the class/pupil has been working on or is about to work on?

$\begin{array}{ll}\text {-Don't know } & \text {-Very well } \\ \text {-Quite well } & \text {-Authored to suit }\end{array}$

2. Does the pupil have to have good keyboard skills to use this program?

only needs to use the arrow/cursor keys

only needs to use the number keys

_only needs to use a restricted number of keys

_ must be able to type (know the keyboard)

_must be able to use the Function Keys

_ must be able to use the SHIFT or CTRL + Function Keys

\section{Multimedia materials}

Multimedia is one of the latest developments in computer technology and it is the concept of integrating sound (included human voice, to high $\mathrm{Q}$ stereo), moving video, graphics and text. These different, yet complementary types of media can be obtained on a single CD-ROM inside an above average computer or standalone multimedia system.

This revolution in new computer technology presents teachers and students with a number of opportunities opening up before them in terms of teaching and learning, however, these type of resources are not yet at the reach of every school or even university and there is still uncertainty of how effective and in what measure, this type of technology can really contribute to the enhancing of language learning. 
HOW, a Colombian Journal of Teachers of English. No. 5. (pp. 63-69). (ISSN: 0120-5927). 1999.

Multimedia language learning is still in its very beginnings and there is still no good pedagogically-based language courseware available from which to choose. However, there are quite a few authoring programs with multimedia capabilities with which teachers can start putting these new high-tech available tools at the service of their pedagogical expertise. The advantage of the multimedia-based approach is that students and teachers can develop their own multimedia materials on a content-free authoring packages like TOOLBOOK, AUTHORWARE PROFESSIONAL, GENESIS III for Windows, OR LING WAY (for IBM compatibles) and Hypercard and Supercard (for Apple MacIntosh)

Multimedia will make possible in the near future to adopt the complete digital language laboratory as opposed to the analogue cassette-based laboratory. At present, costs are still high and the most probable solution for the time being is to have a multimedia resource centre instead, until having multimedia technology as complete laboratories more affordable.

Multimedia is the latest introduction of powerful educational technology as Information Technology in CALL, however, it is very important for teachers and learners not to distract their attention from the real educational goal and the role of technology, which is to support language learning allowing for more diverse, flexible and richer learning contexts.

\section{REFERENCES}

Benavides, J. (1998). Integrating CALL into the Language Curriculum. How, a Colombian Journal of Teachers of English. No. 4. Universidad de Nariño, UDED: San Juan de Pasto.

Brown, G. \& Yule, G. (1983). Teaching the Spoken Language. Cambridge: Cambridge University Press.

Esling, J. (1991). 'Evaluating the spoken and written discourse generated by working with CALL'. In Dunkel P. (ed.) Computer-Assisted Language Learning and Testing. New York: Newbury House.

Jones, C. \& Sue Fortscue. (1987). Using Computers in the Language Classroom. London: Longman.

Krashen, S. (1982). Principles and Practice in Second Language Acquisition. New York: Pergamon Press.

London Adventure, (1983). London: Hamilton.

McDonough, J. \& Shaw, C. (1993). Materials and Methods in ELT: A teachers Guide. Cambridge, Massachusetts: Blackwell.

Rendal, H. (1991). Making the most of micro-computers. London: CILT.

Underwood, J. (1984). Linguistics, Computers and the Language Teacher: A Communicative Approach. Rowley, MA: Newbury House. 